\title{
SEGUROS AGRÍCOLAS BASADOS EN ÍNDICES CLIMÁTICOS: UN ESTUDIO DE CASO EN BOLIVIA
} Ricardo Nogales Carvajal y Pamela Córdova Olivera

\section{RESUMEN}

Los seguros agrícolas basados en índices climáticos son instrumentos financieros novedosos para la gestión de riesgos de agricultores. A diferencia de los seguros tradicionales, éstos pueden mitigar e incluso anular el riesgo moral y la selección adversa, permitiendo abaratar sus primas. Esta característica hace de este tipo de seguros un mecanismo atractivo para economías en vías de desarrollo con gran parte de población rural sumida en severas condiciones de precariedad y, simultáneamente, se promueve el desarrollo de un mercado de seguros agrícolas. Este tipo de seguros no es aún empleado en Bolivia, pero su promoción por parte del aparato público tiene gran potencial de coadyuvar a la seguridad alimentaria y promover el desarrollo económico. El documento presenta algunas experiencias exitosas en el desarrollo de seguros basados en índices climáticos a nivel mundial y analiza el estado actual de desarrollo de este mercado en Bolivia. Se revisan en detalle los fundamentos técnicos de la creación de este tipo de seguros, a partir de los cuales, se presentan propuestas de esquemas paramétricos de seguros agrícolas basados en índices climáticos para la protección de cultivos de trigo y papa, ambos de ciclo intermedio, en el municipio de Anzaldo (sur-oeste de Cochabamba).

Palabras Clave: Índices Climáticos, Seguridad Alimentaria, Mercado de Seguros, Seguros Agrícolas, Desarrollo Económico. 